\title{
HUBUNGAN ANTARA MUSIM DENGAN KADAR CAULERPIN DALAM Caulerpa racemosa
}

\author{
Hedi Indra Januar, Thamrin Wikanta dan Emma Hastarini")
}

\begin{abstract}
ABSTRAK
Makroalga hijau Caulerpa racemosa dipanen pada dua musim berbeda, yaitu pada musim penghujan (Mei 2003) dan pada musim kemarau (Agustus 2003). Senyawa caulerpin diekstrak dari Caulerpa racemosa dengan metanol, kemudian ekstrak metanol tersebut dihitung rendemennya dan dianalisis kadar caulerpinnya. Spektra FTIR dari ekstrak metanol menghasilkan puncak-puncak absorpsi yang khas pada frekuensi $3500 \mathrm{~cm}^{-1}(-\mathrm{OH}), 1638 \mathrm{~cm}^{-1}(-\mathrm{NH}), 1421 \mathrm{~cm}^{-1}$ $(-\mathrm{C}=\mathrm{C}-)$, dan $1168 \mathrm{~cm}^{-1}(-\mathrm{O}-)$. Hasil penelitian menunjukkan bahwa rendemen ekstrak metanol pada musim penghujan $(3,49 \%)$ lebih tinggi dari pada musim kemarau $(2,22 \%)$. Perhitungan kadar caulerpin dilakukan berdasarkan log [Po/P] puncak karakteristik spektra Fourier TransferInfra Red (FT-IR). Hasil perhitungan menunjukkan bahwa konsentrasi caulerpin pada musim penghujan 19,4\% lebih tinggi daripada musim kemarau.
\end{abstract}

ABSTRACT: Relationship between season and the content of caulerpin in Caulerpa racemosa. By: Hedi Indra Januar, Thamrin Wikanta and Emma Hastarini

Green macroalgae Caulerpa racemosa was harvested in two different seasons, i.e. at rainy season (May 2003) and dry season (August 2003). The caulerpin compound was extracted from Caulerpa racemosa with methanol. The yield of methanol extract was then calculated and the content of caulerpin was analyzed. The FTIR spectrum of the methanol extract gave the peaks with the specific absorbance at the frequency of $3500 \mathrm{~cm}^{-1}(-\mathrm{OH}), 1638 \mathrm{~cm}^{-1}(-\mathrm{NH}), 1421 \mathrm{~cm}^{-1}(-$ $\mathrm{C}=\mathrm{C}-)$, and $1168 \mathrm{~cm}^{-1}(-\mathrm{O}-)$. Research revealed that the yield of methanol extract in the rainy season (3.49\%) was higher than that of dry season (2.22\%). The caulerpin content which was calculated based on its $\log [\mathrm{Po} / \mathrm{P}]$ of caracteristic peak at Fourier Transfer-Infra Red (FT-IR) spectrum, showed that in rainy season caulerpin concentration was $19.4 \%$ higher than that of dry season.

KEYWORDS: Caulerpa racemosa, caulerpin and season effect.

\section{PENDAHULUAN}

Alga laut merupakan tumbuhan yang hidup di air laut dan mempunyai komposisi kimia yang berbeda dengan tumbuhan darat. Perbedaan ini sebagai akibat dari terjadinya alur sirkulasi nutrien dari sel-sel alga dengan air laut di sekitarnya, yang tidak terjadi pada sel-sel tumbuhan darat. Hasil adaptasi terhadap lingkungannya ini membuat sel-sel alga laut mampu memproduksi berbagai senyawa unik melalui siklus produksi metabolit sekunder (Portito \& Reina, 2001) yang tidak sama dengan tumbuhan darat

Organisme tingkat tinggi seperti manusia dan hewan lebih mengandalkan kemampuan fisiknya untuk beradaptasi dengan lingkungan hidupnya, sedangkan tumbuhan akan beradaptasi melalui kemampuannya dalam memproduksi senyawa kimiawi (Mann, 1994).
Alga sebagai tumbuhan air, juga akan mengandalkan kemampuannya dalam memproduksi senyawasenyawa khusus untuk beradaptasi dengan lingkungannya. Oleh karena itu, riset akan difokuskan untuk meneliti kandungan senyawa aktif dari alga sebagai upaya proses adaptasinya terhadap lingkungan yang selalu berubah pada setiap musim. Jika adaptasi sel alga terhadap lingkungan terkait dengan kemampuannya menghasilkan senyawa kimia, maka dapat dihipotesis bahwa kandungan senyawa aktif di dalam alga akan berfluktuasi mengikuti perubahan lingkungannya yang berkaitan dengan musim.

Parameter yang diuji adalah kuantitas senyawa aktif pada alga sebagai hasil produksi pada musim yang berbeda, yaitu pada musim penghujan dan musim kemarau. Musim akan membuat suatu

Peneliti pada Pusat Riset Pengolahan Produk dan Sosial Ekonomi Kelautan dan Perikanan 
keadaan lingkungan yang berbeda, misalnya: sifat fisiko-kimia $(\mathrm{pH}$, kelarutan oksigen, daya hantar panas, daya hantar listrik, intensitas sinar matahari, kuantitas dan kualitas nutrien) dan juga kuantitas interaksi-organisme yang ada.

Makroalga hijau Caulerpa racemosa adalah salah satu jenis makroalga yang potensial untuk diteliti. Makroalga ini tumbuh subur di perairan pantai karang selatan pulau Jawa. Aguilar-Santos \& Doty (1968) menerangkan bahwa jika alga ini terluka, maka di daerah luka tersebut akan ditemukan suatu senyawa yang berperan aktif dalam perbaikan/penyembuhan luka pada sel tumbuhan tersebut, yang disebut caulerpin.

Studi literatur yang telah dilakukan menunjukkan bahwa pengaruh interaksi musim terhadap kandungan senyawa aktif Caulerpa racemosa telah dilakukan oleh Paul (2002) terhadap senyawa caulerpenin. Hasil riset yang dilakukannya menemukan bahwa konsentrasi caulerpenin tergantung kepada interaksi ekologis alga dengan hewan predatornya. Namun sampai sejauh ini belum dilakukan riset untuk menentukan pengaruh musim terhadap konsentrasi caulerpin, yang juga merupakan senyawa aktif Caulerpa racemosa. Oleh karena itu, penelitian ini dilaksanakan untuk mengetahui hubungan antara perbedaan musim dengan kadar senyawa aktif caulerpin dalam Caulerpa racemosa.

\section{BAHAN DAN METODE}

Bahan yang digunakan adalah sampel makroalga Caulerpa racemosa, hasil panen di perairan pantai karang Binuangeun, Kabupaten Lebak, Banten pada musim penghujan (Mei 2003) dan musim kemarau (Agustus 2003). Sejumlah $1 \mathrm{~kg}$ sampel makroalga segar diblender dan dimaserasi dalam $800 \mathrm{ml}$ pelarut metanol selama 48 jam. Setelah filtrat disaring kemudian residu dimaserasi kembali dengan cara, jenis dan jumlah pelarut yang sama, dilakukan sebanyak tiga kali. Seluruh larutan maserat/ekstrak yang didapatkan kira-kira sebanyak $2400 \mathrm{ml}$ digabung dan dievaporasi dengan menggunakan evaporator vakum hingga volumenya mejadi sekitar $200 \mathrm{ml}$. Sampel dibuat sebanyak dua buah (duplo).

Ekstrak kental tersebut kemudian dipartisi secara bertahap menggunakan pelarut $n$-heksana dan kloroform, masing-masing $300 \mathrm{ml}$, sebanyak 3 kali, hingga didapatkan masing - masing total ekstrak $n$ heksana dan kloroform sebanyak $900 \mathrm{ml}$. Fraksi metanol tersebut kemudian diuapkan dengan menggunakan alat rotary evaporator lalu dikeringkan dengan menggunakan alat pengering beku (freeze dryer). Ekstrak kasar kering ditimbang dan dihitung rendemennya, kemudian kandungan senyawa aktif caulerpin dianalisis melalui intensitas absorpsi gugus fungsinya menggunakan alat spektrometer Fourier Transform-Infra Red (FT-IR). Analisis spektra FT-IR dilakukan terhadap sampel dengan konsentrasi yang sama dan perbandingan ekstrak metanol : $\mathrm{KBr}$ (kalium bromida $)=2,5 \%(5: 200 \mathrm{mg})$, menggunakan alat Perkin Elmer FT-IR pada frekuensi $4000-4500$ $\mathrm{cm}^{-1}$, duration scan number 6 , resolusi $4 \mathrm{~cm}^{-1}$, dan scan speed $0,2 \mathrm{~cm} / \mathrm{s}$.

\section{HASIL DAN BAHASAN}

Makroalga hijau Caulerpa racemosa tumbuh dengan jumlah berlimpah di perairan pantai karang Binuangeun - Banten Selatan, di zona intertidal, dengan kedalaman kurang dari 1 meter. Keadaan lingkungan tempat tumbuh makroalga Caulerpa racemosa di dua musim yang berbeda telah diobservasi langsung di lapangan selama pengambilan sampel berlangsung (selama 3 hari).

Pada musim penghujan (Mei 2003), selama pengambilan sampel terjadi curah hujan yang tinggi dan intensitas cahaya matahari yang lemah karena langit berawan. Pada saat surut, substrat tempat tumbuh makroalga ini masih terendam air dengan kedalaman sekitar $10 \mathrm{~cm}$. Pada musim kemarau (Agustus 2003), matahari bersinar dengan intensitas tinggi tanpa ada hujan selama masa observasi. Pada saat surut, substrat karang hampir terlihat kering, hanya ada beberapa bagian kubangan yang tergenangi air. Secara umum terlihat bahwa substrat tempat tumbuh makroalga ini hanya tergenangi air pada saat pasang.

Paul (2002) dalam risetnya berhasil mengidentifikasi senyawa aktif dari Caulerpa sp dalam fraksi metanol, berupa senyawa metabolit sekunder utama, yaitu: caulerpicin, caulerpenin, dan caulerpin. Caulerpicin adalah senyawa alkohol dengan rantai karbon alifatik panjang yang mempunyai gugus amina dan eter. Senyawa ini yang membuat rasa tumbuhan ini seperti lada (Aguilar-Santos \& Doty, 1968). Caulerpenin adalah senyawa sesquiterpenoids yang mempunyai gugus aldehid. Senyawa ini bersifat toksik terhadap ikan-ikan herbivora dalam habitat terumbu karang (coral reef). Senyawa lain yang merupakan senyawa aktif pada Caulerpa $s p$ adalah caulerpin. Senyawa ini berupa kristal prisma berwarna oranye-

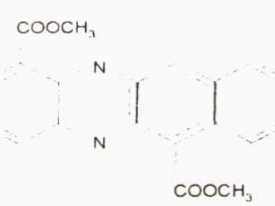

Gambar 1. Struktur kimia senyawa caulerpin. Figure 1. Chemical structure of caulerpin. 
kemerahan memiliki titik leleh $317^{\circ} \mathrm{C}$, dengan struktur seperti terlukis di Gambar 1.

Berdasarkan hasil tersebut, pada penelitian ini ekstrak kasar metanol dipartisi menggunakan pelarut n-heksana dan kloroform untuk memisahkan senyawa aktif dari senyawa-senyawa larut lemak dan zat warna klorofil yang dapat mempengaruhi perhitungan perbandingan senyawa aktif yang dikandung dalam tumbuhan tersebut.

Rendemen ekstrak metanol dari proses pengambilan sampel pada musim penghujan (Mei 2003) adalah $3,49 \% \pm 0,11$, sedangkan pada musim kemarau (Agustus 2004) rendemen ekstrak metanol menurun menjadi $2,22 \% \pm 0,18$. Ekstrak ini kemudian dicuci dengan pelarut $n$-heksana dan kloroform yang mempunyai nilai kepolaran rendah yaitu 0,0 dan 3,4 (Milipore Corporation, 1992). Kedua pelarut ini relatif tidak akan mengekstrak kandungan aktif pada Caulerpa racemosa yang bersifat polar. Harborne (1987) menyatakan bahwa tingkat kemudahan dalam mengisolasi senyawa aktif sangat ditentukan oleh terpisahnya fraksi klorofil dan fraksi lemak yang memiliki tingkat kepolaran rendah.

Hasil ekstraksi senyawa aktif dari sampel hasil panen pada musim kemarau memperlihatkan nilai rendemen ekstrak sebesar $36,4 \%$ lebih rendah dari hasil panen pada musim penghujan. Walaupun nilai rendemen ekstrak sangat rendah, tetapi hal ini belum cukup membuktikan bahwa kandungan senyawa aktif di dalam ekstrak lebih rendah. Oleh karena itu, dilakukan analisis kadar senyawa aktif di dalam ekstrak dengan menggunakan alat spektrometri FTIR. Hasil uji spektrometri dapat dilihat pada Gambar 2.

Spektra inframerah memperlihatkan beberapa puncak gugus fungsi yang penting. Daerah absorpsi lebar pada frekuensi $3000-3600 \mathrm{~cm}^{-1}$ memperlihatkan adanya tumpang tindih antara absorpsi khas gugus fungsi $-\mathrm{OH}$ yang mempunyai ikatan hidrogen dan absorpsi gugus fungsi $-\mathrm{NH}$. Hal ini diperkuat dengan adanya absorpsi khas - $\mathrm{NH}$ pada frekuensi $1638 \mathrm{~cm}^{-1}$. Absorpsi gugus alfa-naftalena terlihat pada frekuensi

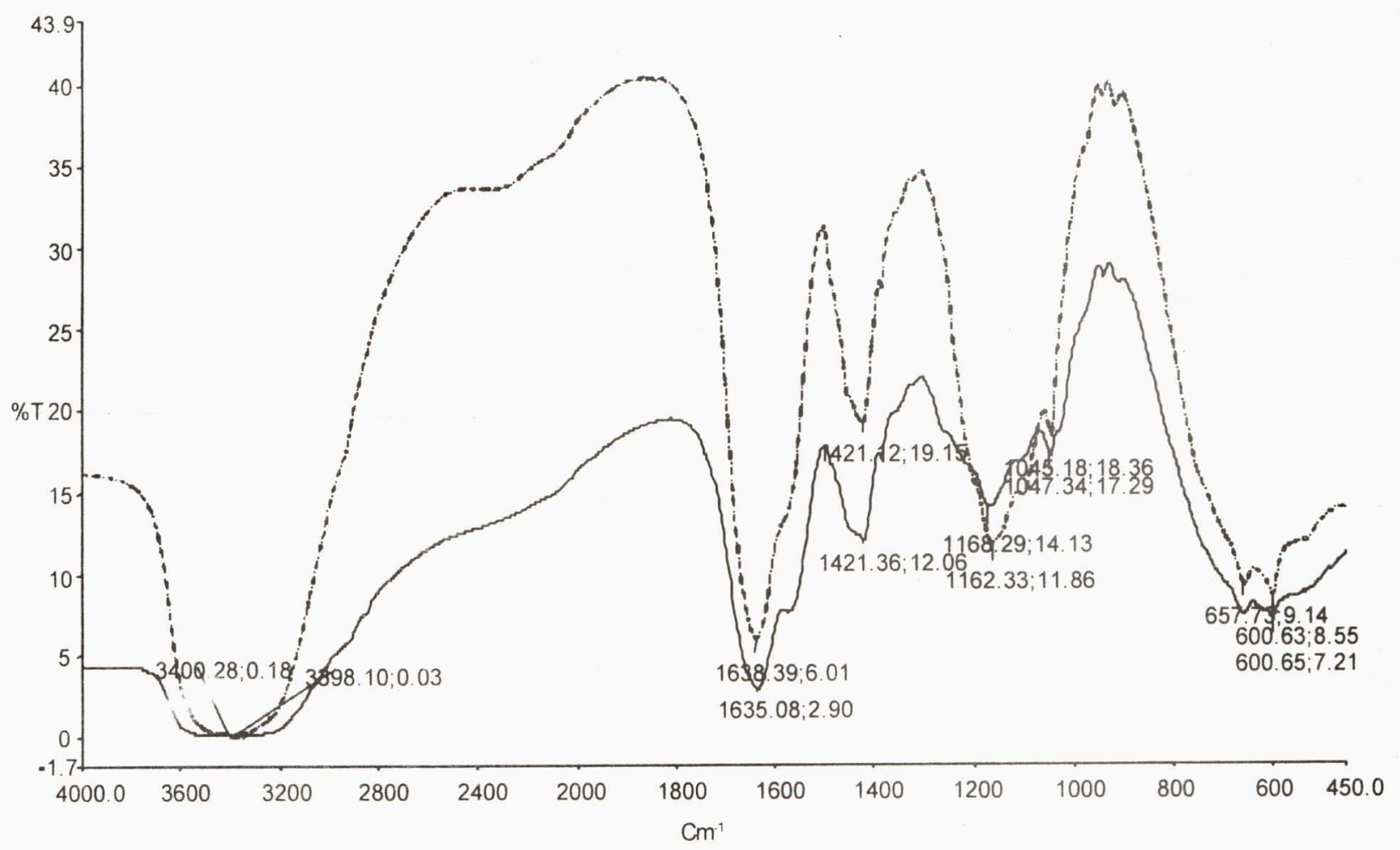

Keterangan/Note:

Musim penghujan/Rainy season

Musim kemarau/Dry season

Gambar 2. Spektra inframerah ekstrak metanol dari Caulerpa racemosa dengan sampel hasil panen pada musim penghujan dan kemarau.

Figure 2. Infrared spectrum of Caulerpa racemosa methanol extract with the sample harvested at rainy and dry season. 
Tabel 1. Nilai frekuensi inframerah ekstrak metanol dari Caulerpa racemosa dan caulerpin standar (Pusecker et al., 1995)

Tabel 1. Infrared frequency of Caulerpa racemosa methanol extract and standard caulerpin (Pusecker et al., 1995)

\begin{tabular}{|c|c|c|c|c|c|c|c|c|c|c|c|c|}
\hline Perlakuan/Treatments & \multicolumn{12}{|c|}{ Frekuensi inframerah//nfrared frequency } \\
\hline $\begin{array}{l}\text { Frekuensi inframerah }\left(\mathrm{cm}^{-1}\right) \\
\text { caulerpin standar (Pusecker et } \\
\text { al., 1997)/Infrared frequency } \\
\left(\mathrm{cm}^{-1}\right) \text { of standard caulerpin } \\
(\text { Pusecker et al., 1997) }\end{array}$ & 3322 & 2958 & 2858 & 1678 & 1607 & 1494 & 1442 & 1330 & 1288 & 1271 & 1226 & 1155 \\
\hline $\begin{array}{l}\text { Frekuensi inframerah }\left(\mathrm{cm}^{-1}\right) \\
\text { ekstrak metanol Caulerpa } \\
\text { racemosa /Infrared frequency } \\
\left(\mathrm{cm}^{-1}\right) \text { of Caulerpa racemosa } \\
\text { methanol extract }\end{array}$ & 3400 & 2900 & 2856 & 1638 & & & 1421 & & & & & 1168 \\
\hline
\end{tabular}

Tabel 1. Nilai frekuensi inframerah ekstrak metanol dari Caulerpa racemosa dan caulerpin standar (Pusecker et al., 1995) (Lanjutan)

Tabel 1. Infrared frequency of Caulerpa racemosa methanol extract and standard caulerpin (Pusecker et al., 1995) (Continued)

\begin{tabular}{|c|c|c|c|c|c|c|c|c|c|c|c|c|}
\hline Perlakuan/Treatments & \multicolumn{12}{|c|}{ Frekuensi inframerah//nfrared frequency } \\
\hline $\begin{array}{l}\text { Frekuensi inframerah }\left(\mathrm{cm}^{-1}\right) \\
\text { caulerpin standar (Pusecker et } \\
\text { al., 1997)/Infrared frequency } \\
\left(\mathrm{cm}^{-1}\right) \text { of standard caulerpin } \\
\text { (Pusecker et al., 1997) }\end{array}$ & 1090 & 1049 & 937 & 889 & 865 & 800 & 751 & 743 & 726 & 690 & 668 & 602 \\
\hline $\begin{array}{l}\text { Frekuensi inframerah }\left(\mathrm{cm}^{-1}\right) \\
\text { ekstrak metanol Caulerpa } \\
\text { racemosa /Infrared frequency } \\
\left(\mathrm{cm}^{-1}\right) \text { of Caulerpa racemosa } \\
\text { methanol extract }\end{array}$ & & 1045 & & & & & & & & & 657 & 600 \\
\hline
\end{tabular}

sekitar $1421 \mathrm{~cm}^{-1}$ dan diperkuat oleh absorpsi sidik jari khas di daerah frekuensi sekitar $650 \mathrm{~cm}^{-1}$. Absorpsi gugus eter (C-O-C) juga terdapat di dalam ekstrak dengan adanya absorpsi khas pada frekuensi $1168 \mathrm{~cm}^{-1}$ dan diperkuat dengan absorpsi khas pada frekuensi sekitar $600 \mathrm{~cm}^{-1}$. Tabel 1. memperlihatkan kemiripan spektra IR ekstrak metanol dengan spektra caulerpin yang dianalisis oleh Pusecker et al. (1995).

Kemiripan pola spektrum dapat terlihat dari nilai frekuensi inframerah spektra pembanding dan frekuensi ekstrak metanol yang didapatkan. Walaupun terlihat bahwa ada beberapa frekuensi ekstrak metanol yang tidak muncul seperti pada frekuensi caulerpin standar, terutama pada daerah sidik jari dengan frekuensi yang lebar, namun karakteristik gugus-gugus fungsi terlihat pada lokasi yang sama. Oleh karena itu, dapat disimpulkan bahwa ekstrak mengandung caulerpin, senyawa aktif dari Caulerpa racemosa. Spektra FTIR memperlihatkan adanya gugusan eter, hal ini mengindikasikan terdapatnya senyawa caulerpicin di dalam ekstrak. Tidak adanya absorpsi antara frekuensi $1700-1800 \mathrm{~cm}^{-1}$ yang merupakan absorpsi khas dari gugus karbonil, menunjukan bahwa ekstrak tidak mengandung senyawa caulerpenin yang mempunyai gugus fungsi aldehid. Sedangkan caulerpin terdeteksi pada frekuensi $1421 \mathrm{~cm}^{-1}$ dan $650 \mathrm{~cm}^{-1}$, yang merupakan absorpsi khas untuk gugus a-naftalena yang dimilikinya.

Perhitungan perbandingan kadar senyawa caulerpin dalam Caulerpa racemosa hasil panen dari dua musim berbeda dilakukan dengan menggunakan Spektrometer FT-IR, berdasarkan hukum Lambert - 
Beer (Nur, 1989) yang menyatakan bahwa hubungan antara spektrum inframerah dan konsentrasi dapat dinyatakan dalam rumus berikut.

$$
\log [\mathrm{Po} / \mathrm{P}]=k \mathrm{C}
$$

Perhitungan kuantitatif dalam spektra inframerah didasarkan pada Hukum Lambert - Beer, dengan membandingkan antara log [Po/P] terhadap konsentrasi (Willard et al, 1974). Oleh karena itu, jika log [Po/P] pada frekuensi khas gugus fungsi khas dari senyawa caulerpin dibandingkan, maka akan dapat diketahui perbandingan konsentrasi senyawa tersebut yang terdapat pada sampel hasil panen pada musim penghujan dan musim kemarau. Frekuensi yang digunakan untuk menghitung perbedaan kandungan caulerpin adalah $1421 \mathrm{~cm}^{-1}$, karena frekuensi tersebut menyatakan cincin ikatan rangkap terkonjugasi (a-naftalena) yang dimiliki oleh caulerpin. Gambar 3 berikut memperlihatkan perbandingan $\mathrm{Po} /$ $P$ untuk masing-masing musim.

Perhitungan perbandingan kosentrasi Caulerpin pada kedua musim tersebut dapat dihitung sebagai berikut.

$$
\frac{\log (19,15 / 12,06)}{\log (33,33 / 19,15)}=\frac{\text { [musim kemarau] }}{\text { [musim penghujan] }}
$$

$$
\text { [musim penghujan] }=1,194 \text { [musim kemarau] }
$$

Perbandingan [Caulerpin]=

([musim penghujan] : [musim kemarau]) $\times 100 \%=$ $119,4 \%$

Secara umum dapat dikatakan bahwa Caulerpa racemosa mampu memproduksi senyawa aktif caulerpin pada kedua musim karena berbagai faktor, baik nutrien maupun keadaan fisiko-kimia yang diperlukan untuk mensintesis senyawa ini agar tersedia dalam jumlah yang cukup. Namun demikian, hasil perhitungan di atas memperlihatkan bahwa kuantitas senyawa aktif caulerpin yang dikandung Caulerpa racemosa, dipengaruhi oleh musim. Hasil perhitungan menunjukkan bahwa kadar caulerpin dalam sampel hasil panen pada musim penghujan $19,4 \%$ lebih besar daripada sampel hasil panen pada musim kemarau.

Mann (1994) menyatakan bahwa produksi senyawa metabolit sekunder yang dilakukan oleh suatu organisme dapat merupakan suatu hasil samping metabolisme yang tidak memiliki efek apapun terhadap organisme yang memproduksinya atau merupakan suatu bagian penting dalam pertahanan hidup oganisme tersebut. Oleh karena itu, untuk dapat menyimpulkan hubungan antara musim

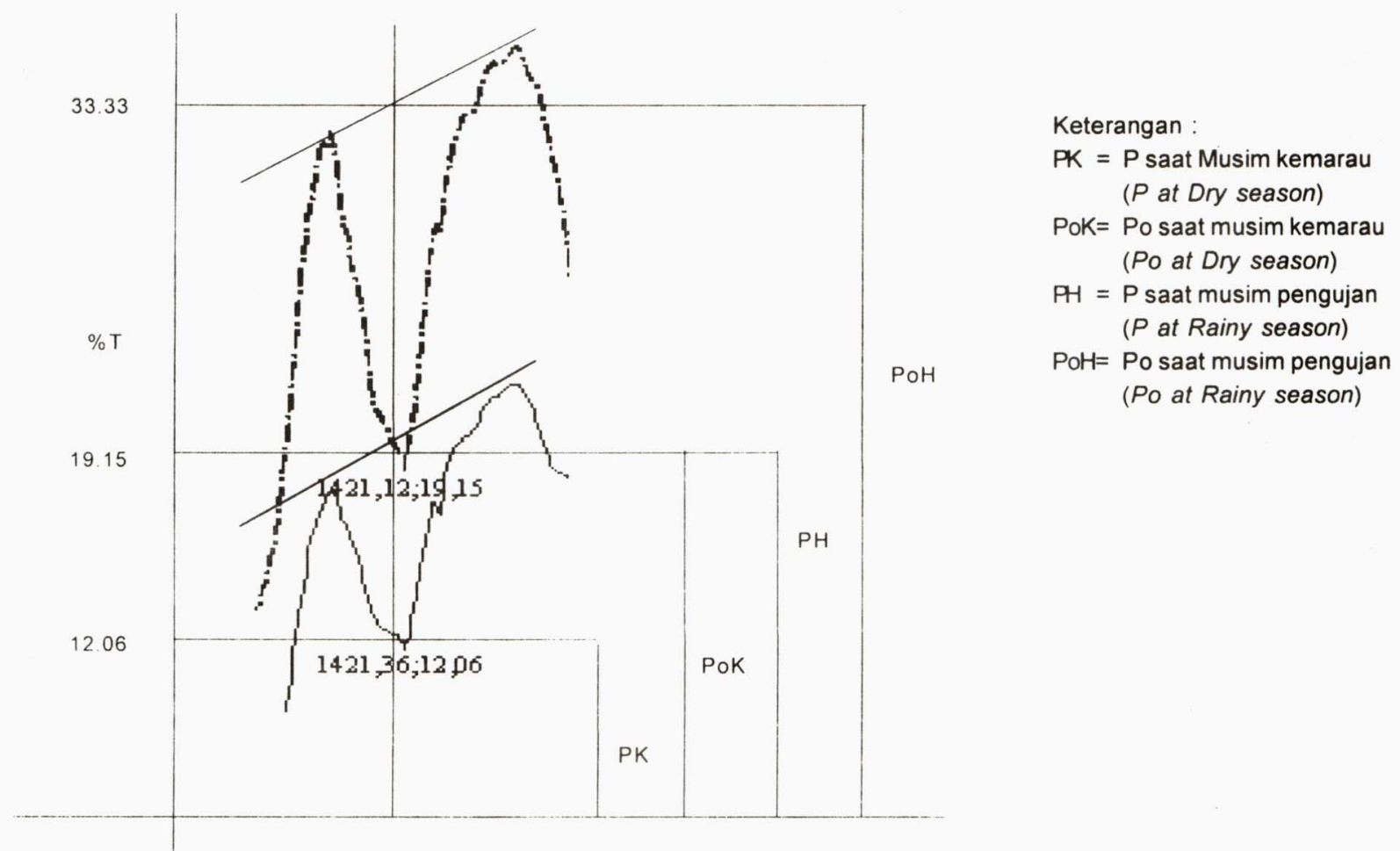

Gambar 3. Perbandingan Po/P pada frekuensi $1421 \mathrm{~cm}^{-1}$

Figure 3. Po/P ratio at frequency $1421 \mathrm{~cm}^{-1}$ 
dengan kadar senyawa aktif metabolit sekunder, penjelasan harus dikaitkan terhadap fungsi dan efek senyawa bioaktif terhadap organisme produsennya.

Dikemukakan oleh Aguilar-Santos \& Doty (1968), caulerpin merupakan senyawa metabolit sekunder dari Caulerpa racemosa yang berperan jika alga ini terluka. Pada permukaan luka, akan terlihat suatu lendir berwarna kemerahan yang akan menutupi permukaan luka dan menyembuhkan atau memperbaiki kerusakan sel akibat luka tersebut. Berdasarkan fungsi dan bioaktivitas yang dimiliki oleh senyawa tersebut maka dapat disimpulkan bahwa senyawa ini adalah suatu senyawa metabolit sekunder yang berperan penting didalam fungsi pertahanan Caulerpa racemosa.

Mann (1994) menerangkan bahwa beberapa metabolit sekunder tumbuhan yang mempunyai fungsi pertahanan akan diproduksi meningkat sebagai respons adaptasi yang dilakukan tumbuhan tersebut terhadap perubahan kimia-ekologi yang terjadi. Peningkatan caulerpin pada musim penghujan kemungkinan disebabkan karena meningkatnya predator herbivora air terhadap alga Caulerpa racemosa. Kondisi ini mengakibatkan Caulerpa racemosa mengalami banyak luka dan harus beradaptasi dengan meningkatkan produksi caulerpin agar dapat bertahan hidup.

Keberadaan senyawa metabolit sekunder Caulerpa racemosa ini juga dapat digunakan untuk memprediksi jenis herbivora air yang terdapat di lingkungan tumbuh Caulerpa racemosa tersebut. Herbivora air yang biasa memakan alga ini adalah siput laut (sea snails), bulu babi (sea-urchins), dan ikan - ikan herbivora (Paul, 2002). Tidak diproduksinya caulerpenin yang toksik terhadap ikan herbivora dan bulu babi mengindikasikan bar a herbivora tersebut tidak terdapat dalam ekosistem alga ini dan kemungkinan yang hidup di lingkungan tersebut adalah golongan siput laut. Hal ini didukung oleh hasil penelitian Paul (2002) yang menemukan bahwa pada suatu daerah di pesisir pantai Mediterania dimana tidak terdapat ikan herbivora dan bulu babi, caule, perin juga tidak terdeteksi di dalam ekstrak kasar metanol dari alga ini. Namun, perlu dilakukan penelitian lebih lanjut untuk membuktikan fenomena ini.

\section{KESIMPULAN DAN SARAN}

Hasil riset ini menjelaskan bahwa musim berperan terhadap produksi senyawa aktif caulerpin yang dimiliki oleh alga hijau Caulerpa racemosa, yaitu saat musim penghujan produksi caulerpin lebih banyak dibandingkan dengan musim kemarau.

Hasil riset ini perlu dilanjutkan untuk membuktikan fenomena hubungan antara kuantitas predator dengan produksi caulerpin oleh Caulerpa racemosa. Selain itu, perlu dilakukan isolasi dan identifikasi senyawa aktif dari Caulerpa racemosa.

\section{DAFTAR PUSTAKA}

Aguilar-Santos, G. and Doty, M.S. 1968. Drugs From The Sea. Marine Technology Society. Washington D.C. 173 $\mathrm{pp}$.

Nur, N.A., 1989. Bahan Pengajaran Spektroskopi. Institut Pertanian Bogor. Bogor. $28 \mathrm{pp}$.

Harborne, J.B. 1987. Metode Fitokimia - Penuntun Cara Modern Menganalisis Tumbuhan-. Penerjemah Padmawinata, K. dan Soediro, I. Terbitan Kedua. Penerbit ITB. Bandung. p. 6-7.

Mann, J. 1994. Chemical Aspects of Biosynthesis. Oxford University Press. New York. p. 2, 81

Milipore Corporation. 1992. Waters Sep-Hak Catridge Care and Manual -. Waters Chromatography Publications. Milford. $13 \mathrm{pp}$.

Paul V.J. 2002. Chemical Ecology of Caulerpa spp with an Emphasis on Invasive Caulerpa taxifolia. University of Guam Marine Labolatory.

Portito, E. and Reina, G.G. 2001. Screening of Antimicrobial Activities in Red, Green, and Brown Macroalgae from Gran Canaria Spain. International Microbiol. Springer - Verlag \& SEM. Spain. 39 pp.

Pusecker K., Laatsch H., Helmke E., and Weyland H. 1995. Dihydrophencomycin methylester, a New Phenazine Derivative from a Marine Streptomycete. Liebigs Ann. Chem. p. 1291-1294.

Willard H.H., Merritt, L.L. Jr., and Dean J.A. 1974. Instrumental Methods for Analysis. Fifth Edition. D.Val Nostrand Company. New York. p. 108, 170. 